\title{
New approach for complete endocardiectomy in left ventricular endomyocardial fibrosis
}

\author{
Raja Joshi, MCh \\ Smartin Abraham, MS \\ Arkalgud Sampath Kumar, MCh
}

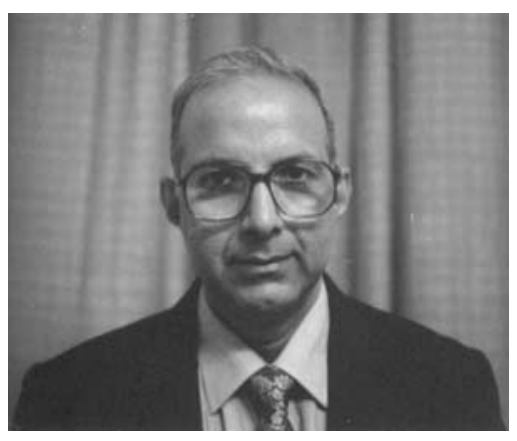

Dr Kumar

From the Department of Cardiothoracic and Vascular Surgery, All India Institute of Medical Sciences, New Delhi, India.

Received for publication April 23, 2001; revisions requested Jan 23, 2002; revisions received April 23, 2002; accepted for publication May 1, 2002.

Address for reprints: A. Sampath Kumar, MCh, Professor, Department of Cardiothoracic and Vascular Surgery, AIIMS, Ansari Nagar, New Delhi, 110029, India. (E-mail: asampath_kumar@hotmail.com).

J Thorac Cardiovasc Surg 2003;125:40-2

Copyright (C) 2003 by The American Association for Thoracic Surgery

$0022-5223 / 2003 \$ 30.00+0$

doi: $10.1067 / \mathrm{mtc} .2003 .70$
Intracardiac exposure for excision of the endocardium during surgery for endomyocardial fibrosis has previously been achieved through the atrium, the ventricle, and the interatrial septum. Poor visualization of the apex and lateral wall of the left ventricle poses difficulties in complete resection of the thickened endocardium in these regions, leading to residual problems. We describe a transaortic-transatrial approach for excellent visualization and successful total endocardiectomy of left ventricular endomyocardial fibrosis. This approach is feasible, easy, and safe.

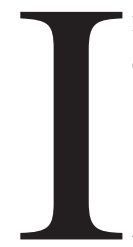

$\mathrm{n}$ this report we describe a new approach for the surgical treatment of endomyocardial fibrosis.

\section{Patient and Method \\ Clinical Summary} exertional dyspnea (New York Heart Association functional class III) and palpitations of 3 to 4 months in duration. No history suggestive of a rheumatic origin was forthcoming.

Clinical examination revealed cardiac enlargement, hyperdyanamic precordium and a harsh (grade 4/6) systolic murmur at the apex. Chest radiography showed cardiomegaly, biatrial enlargement, and pulmonary venous hypertension. Electrocardiography showed changes consistent with left ventricular hypertrophy.

Transthoracic echocardiography revealed prolapse of the anterior mitral leaflet with severe $(4+)$ mitral regurgitation, enlarged left atrium $(50 \mathrm{~mm})$, and dilated left ventricle $(46 \mathrm{~mm}$ at end-diastole and $26 \mathrm{~mm}$ at end-systole). The aortic anulus measured $23 \mathrm{~mm}$ (Figure 1, $A$ and $B)$. Left ventricular ejection fraction was $55 \%$ with diastolic dysfunction (E wave/A wave ratio of 1.2:0.2 and deceleration time of $130 \mathrm{~ms}$ ). Color flow mapping showed severe mitral regurgitation and severe tricuspid regurgitation. Peak tricuspid regurgitation velocity was $3.77 \mathrm{~m} / \mathrm{s}$, and calculated pulmonary artery systolic pressure was $67 \mathrm{~mm} \mathrm{Hg}$. Cardiac catheterization and angiography (Figure 2) showed obliteration of the left ventricular apex, severe mitral regurgitation, and a left ventricular end-diastolic pressure of $28 \mathrm{~mm} \mathrm{Hg}$. An endomyocardial biopsy specimen was strongly suggestive of left ventricular endomyocardial fibrosis. Transesophageal echocardiography revealed prolapse of the anterior mitral leaflet, a fixed posterior mitral leaflet, and thickened left ventricular endocardium.

\section{Surgical Technique}

Sternotomy and aortobicaval cannulation were performed. Hypothermic cardiopulmonary bypass at $32^{\circ} \mathrm{C}$ was initiated. Myocardial protection was achieved by aortic root injections of cold $\left(8^{\circ} \mathrm{C}\right)$ blood cardioplegic solution and topical cooling with ice slush. Left atriotomy was made posterior and parallel to the interatrial groove.

The anterior mitral leaflet was thin and pliable, and the posterior leaflet was thickened with entrapment of its papillary muscle in the fibrosis within the left ventricle. The anulus was dilated with poor leaflet coaptation, and central mitral regurgitation was noted. The anterior leaflet was retracted with a Mayo leaflet retractor.

Leathery, white, thickened endocardium was seen as two patches obliterating the left ventricular cavity, with a narrow skip area separating them. The smaller patch (Figure 3) involved the posterior wall, starting from behind the posterior leaflet extending apically up to the insertion of the posterior medial papillary muscle base. It measured approximately $40 \times$ $30 \mathrm{~mm}$ and was $2 \mathrm{~mm}$ thick. The larger patch (Figure 3) measured $45 \times 37 \mathrm{~mm}$ and was 3 

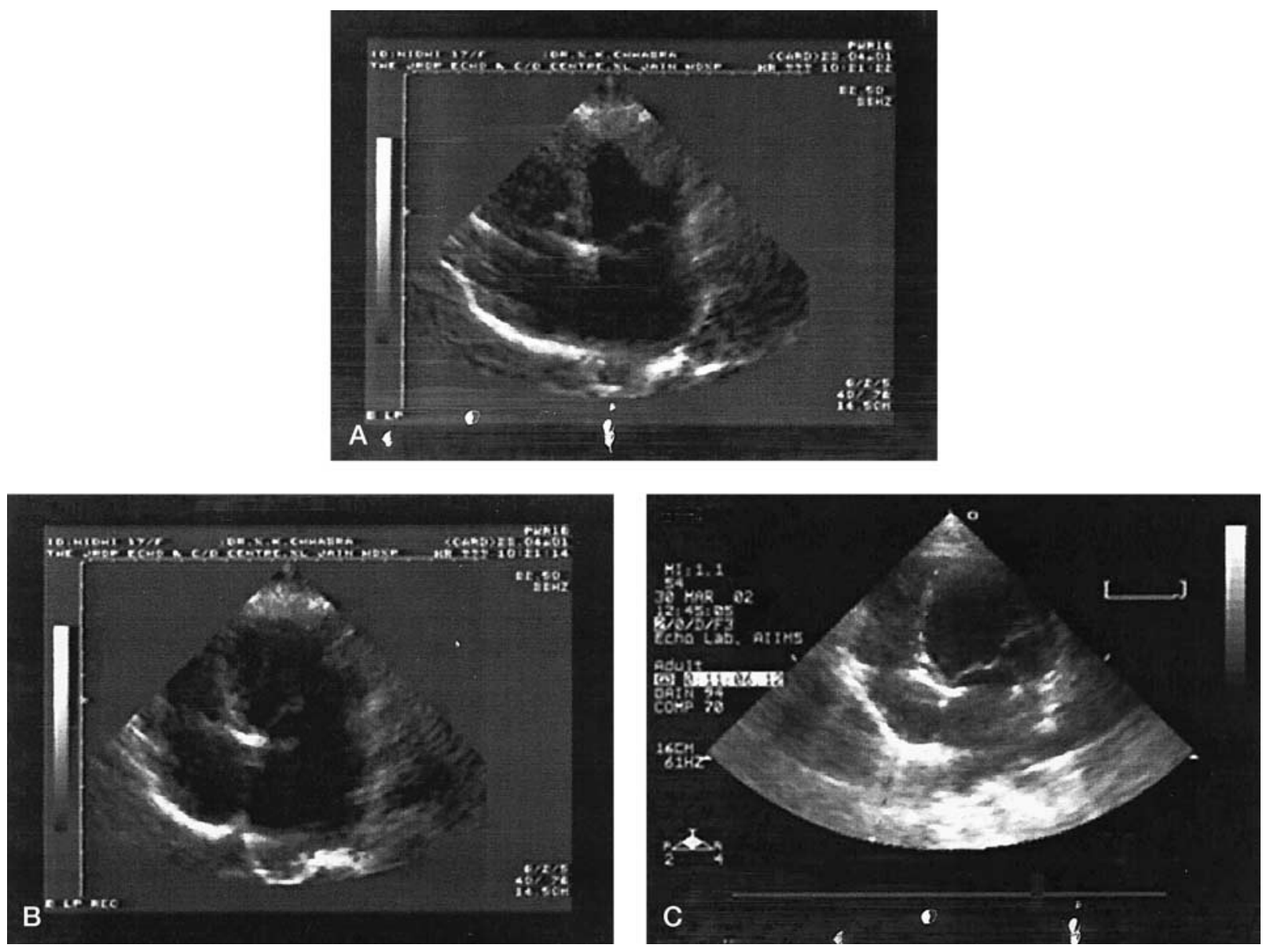

Figure 1. Transthoracic echocardiograms. Apical four-chambered view. A, Preoperative systolic. B, Preoperative diastolic. C, Postoperative systolic.

mm thick. It was located at the apex and continued over the adjoining septum. The outflow portion was free.

Endocardiectomy of the posterior wall was begun in the manner described by Metras and colleagues. ${ }^{1}$ Dissection was started from behind the posterior leaflet by developing a plane between the endocardium and myocardium with a No. 11 surgical blade. The separated edge of the diseased endocardium was held with Allis forceps, and further separation was done by sharp dissection. The base of the involved posteromedial papillary muscle was carefully freed from entrapping fibrous tissue and was excised piecemeal.

Excision of the anterior and septal patch at the apex through the intact mitral orifice was difficult because of poor visibility and access. A transverse aortotomy was made $5 \mathrm{~mm}$ above the origin of right coronary artery. A deep-bladed retractor was passed into the left ventricular outflow to retract the normal aortic valve. Excellent visualization of the left ventricular apex and adjoining septum facilitated endocardiectomy in that area in the same way as described previously. The aortotomy was closed. Cuspal thinning and posterior annuloplasty were performed as described previously elsewhere..$^{2,3}$ The left atriotomy was repaired.

After rewarming and deairing, cardiopulmonary bypass was discontinued. Transesophageal echocardiography confirmed a competent mitral valve.

\section{Results}

The patient made an uneventful recovery and was discharged on the fifth postoperative day. Postoperative echocardiography showed trivial mitral regurgitation, mild left ventricular systolic dysfunction (left ventricular ejection fraction $50 \%$ ), and markedly improved diastolic function.

At 7 months of follow-up, the patient was in New York Heart Association functional class I. Echocardiography showed trivial mitral regurgitation (Figure 1,C), improved systolic (left ventricular ejection fraction 60\%) and diastolic left ventricular function ( $\mathrm{E}$ wave to $\mathrm{A}$ wave ratio of 1:0.6 and deceleration time of $190 \mathrm{~ms}$ ), and regression of left ventricular dimensions (end-diastolic $40 \mathrm{~mm}$, end-systolic $20 \mathrm{~mm})$.

\section{Discussion}

Metras and colleagues ${ }^{1}$ strongly advocate complete endocardiectomy as the treatment of choice for endomyocardial fibrosis or Davies disease. The rationale provided was based on absence of recurrence after complete resection. It is almost always possible to achieve resection, because there is 


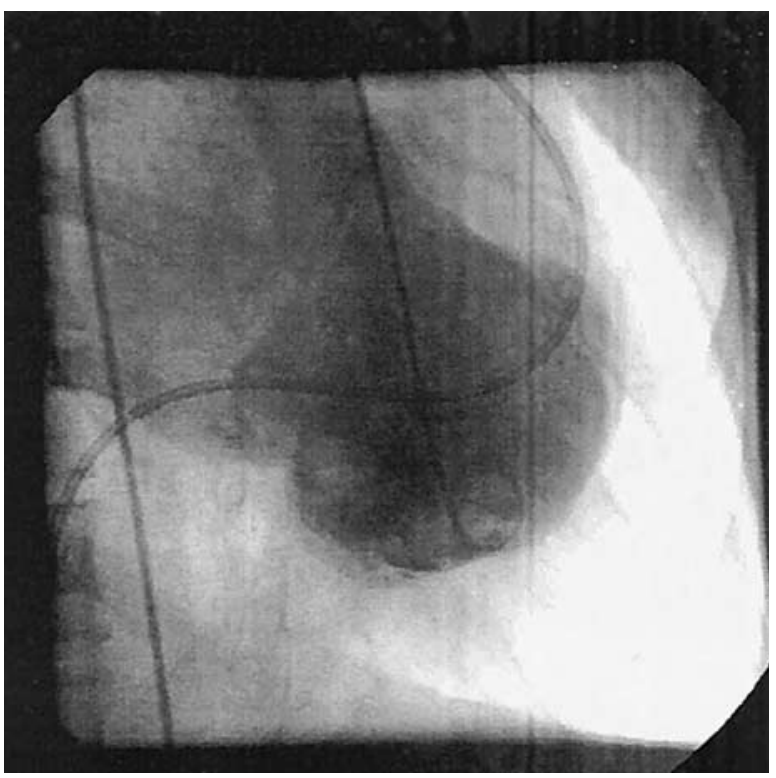

Figure 2. Left ventricular angiogram showing apical obliteration, patchy filling defects, and severe mitral regurgitation.

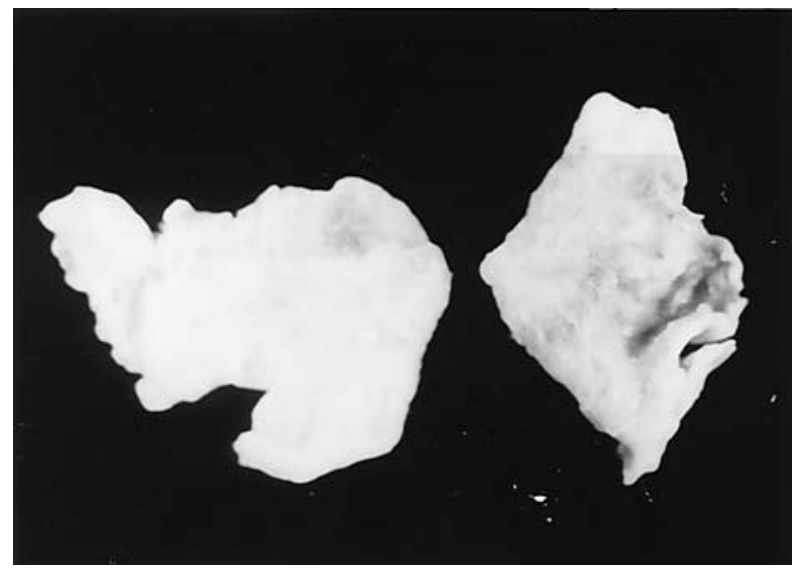

Figure 3. Excised endocardial patches. Larger (left) measured $45 \times 37 \times 3 \mathrm{~mm}$ and was located at apex. Smaller (right) measured $40 \times 30 \times 2 \mathrm{~mm}$ and was excised from posterior wall.

a well-defined plane between the fibrosed endocardium and the normal myocardium. The associated atrioventricular valve regurgitation may be repaired or the valve may be replaced, according to the involvement of the valvular apparatus.

Dubost and associates ${ }^{4}$ described the transatrial approach for surgical treatment of left ventricular endomyocardial fibrosis. Difficulty in visualizing the diseased endocardium in the apical region, especially in cases in which the mitral valve was being conserved, prompted surgeons to look for newer approaches.5,6 Lepley and colleagues ${ }^{7}$ applied a transventricular approach for such cases. This involved incision over the left ventricular apex and carried potential risks of bleeding, arrhythmia, dysfunction, and possibly late aneurysm formation.

Endomyocardial fibrosis usually spares the left ventricular outflow tract and semilunar valves. Thus access into the left ventricle to clearly visualize the apical area can be obtained through the transaortic route. To our knowledge, left ventricular endocardial excision has not previously been performed through the aorta.

This approach provides a complete visualization of the left ventricular endocardium, especially when the mitral valve apparatus is being preserved. Some authors ${ }^{8}$ believe that resection of the mitral valve apparatus is necessary for excision of the entire left ventricular endocardium. We believe that a combined transaortic-transatrial approach is feasible, is safe, and provides the following advantages. Exposure and excision of the left ventricular endocardium are complete. The technique avoids left ventricular incision and its consequences. The approach provides an opportunity to conserve the mitral valve. Finally, it avoids damage to the mitral valve apparatus as a result of excessive retraction to obtain access into the left ventricle.

\section{References}

1. Metras D, Coulibaly AQ, Quattara K. Recent trends in the surgical treatment of endomyocardial fibrosis [review]. J Cardiovasc Surg. 1987;28:607-13.

2. Choudhary SK, Talwar S, Dubey B, Chopra A, Saxena A, Kumar AS. Mitral valve repair in predominantly rheumatic population: long-term results. Tex Heart Inst J. 2001;28:8-15.

3. Kumar AS, Rao PN. Restoration of pliability of the mitral leaflets during reconstruction. J Heart Valve Dis. 995;4:251-3.

4. Dubost C, Maurice P, Gerbaux D, Rulliere R, Barillon A, Bert Cand $\mathrm{E}$, et al. L'endocardite fibreuse constrictive treatment chirurgical. Arch Mal Coeur. 1977;70:155-62.

5. Binet JP, Pernod J, Kermarec J, Colelle J, Weiler M, Bouhey J, et al. Endocardite constrictive fibroplastique: á propose d'une forme localise'e au ventricule gauche. Arch Mal Coeur. 1977;70:163-8.

6. de Oliveira SA, Pereira Barreto AC, Mady C, Dallan LA, da Luz PL, Jatene AD, et al. Surgical treatment of endomyocardial fibrosis: a new approach. J Am Coll Cardiol. 1990;16:1246-51.

7. Lepley D, Aris A, Korns ME, Walker JA, D'Cunha RM. Endomyocardial fibrosis: a surgical approach. Ann Thorac Surg. 1974;18:62633.

8. Carlos RM, Buffolo E, Lima R, Victor E, Lira V, Escobar M, et al. Surgical treatment of endomyocardial fibrosis. J Thorac Cardiovasc Surg. 1983;85:738-45. 